\title{
Pathological Fracture Of Long Bone Secondory To Tophious Gout - A Case Report And Revew Of Literature
}

\author{
Dr. Deepak Mantri *, Dr. Susheel Soni**, Dr. D K Sharma*** \\ Dr. Sikha Ghanghoria**** \\ *Assistant professor, Department of orthopaedics, MGM Medical college, Indore, India \\ **PG Student, Department of orthopaedics, MGM Medical college, Indore, India \\ ***siniar consultant, Department of orthopaedics, MGM Medical college, Indore, India \\ **** Assistant professor, Department of pathology, MGM Medical college, Indore, India
}

\begin{abstract}
Gout is a systemic metabolic disease affecting more than $1 \%$ of the population. Four clinical stages (asymptomatic hyper uricemia, acute gouty arthritis, interstitial gout, and chronic tophaceous gout) are described. Tophi may appear at any site, but the most common sites are the digits or the ears, hand and of the the feet and the olecranon bursa. A 28-year-old man sustained fracture on tibia after trivial trauma in same limb operated 10 year back. Intraoperativly at fracture site there is massive chalky white deposit found. After thorough investigation of patient and histopathological examination of deposit found that patient has high normal level of serum uric acid. Biopsy report shows touphious deposit. All other differential diagnosis chalky white material was ruled out. Patient did not have any history and clinical feature of any joint involment. We present a case of postoperatively deposition of gouty tophi in subclinical gout in around 10 year old implant of tibia and causes pathological fracture of long bone after trival trauma.
\end{abstract}

Key words: Gout, tophy, pathological fracture

\section{Introduction}

Gout is a systemic metabolic disease affecting more than $1 \%$ of the population. Four clinical stages (asymptomatic hyper uricemia, acute gouty arthritis, intersriticial gout, and chronic tophaceous gout) are described. Chronic tophaceous gout usually develops 10 or more years of acute intermittent gout, although in rare cases tophi may be the initial manifestation of the disease. Tophi may appear at any site, but the most common sites are the digits or the ears, hand and of the the feet and the olecranon bursa. Also, tophi may be associated with destructive deforming arthritis. In these cases the differential diagnosis with other types of arthritis should be done. We present a case of 28 year male postoperatively deposition of gouty tophi around 10 year old implant of tibia and causes pathological fracture of long bone after trivial trauma. patient did not have any history and clinical feature of any joint involment.

\section{Case Presentation}

A 28-year-old man sustained fall on ground 10 days back and was admitted to the Department of Orthopaedics and Traumatology at MY Hospital and MGM medical college indore with complaint of pain in proximal leg and inability to bear weight on right leg and had history of fracture on the same leg 10 year back. On local examination tenderness in proximal leg and slight abnormal mobility seen. $\mathrm{X}$ ray was done and diagnosed it was an old operated case of fracture tibia fibula middle third with refracture just proximal to tibia plate (fig 1). On obtaining history there were 10 year old trauma due to RTA for which tibia platting done. After some time patient mobilise, fracture healed patient went to daily routine work as previous. Patient didn't have any other significant medical and surgical history. No history joint pain or joint related complaint.

On the basis of clinical examination, history, $\mathrm{x}$ ray, plan for implant removal and re-plating. But incidentally intraoperatively when implant exposed there was thick chalky white deposit around the implant and within the bone in fracture site was present. Implant with some broken screw was removed. all chalky white material removed by Curettage. bone at fracture site and near implant was very fragile bone. Now fracture fixation postponded, wound closed and chalky white material sent for biopsy and culture sensitivity.

Postoperatively patient thoroughly investigated for etiology of chalky white deposit. Differantial diagnosis of chalky white deposit are gout, hypothyroidism, hyperparathyroidism, hemocromatosis, hypomagnesimia. Blood tests showed a normal complete blood cell count and normal liver function test.. Renal function was normal. The serum creatinine level, serum urea level was normal, erythrocyte sedimentation rate was $40 \mathrm{~mm} /$ hour (normal range, 0 to $20 \mathrm{~mm} /$ hour). serum uric acid level was $7.0 \mathbf{~ m g} / \mathbf{d l}$ (normal range, 3.4 $7.0 \mathrm{mg} / \mathrm{dl}$ ) toward high normal may be the subclinical gout.Thyroid function test are normal TotalT3 - 1.5 
(range 0.60-1.81) Total T4 9.1 (range 4.5-12.6) no hypothyroidism ditected. Intact PTH 40.3 ( range 15-68.3 $\mathrm{pg} / \mathrm{ml}$ ) exclude hyperparathyroidism . serum ferritin level 58.2 ( range 18.70-323 ng/ml) serum iron level 49 microgm/dl TIBC 301 (RANGE 250-450mcgm/dl) Transferring saturation index 16.3\% (range 15-50) shows narmal iron metabolism and no hemocromatosis. serum magnesium level 2.1 (range 1.8-2.6mg/dl) is narmal,no hypomagnesimia. serum calcium 9.4( range 8.5- $10.1 \mathrm{mg} / \mathrm{dl}$ ) Intact PTH 40.3 ( range 15-68.3 pg/ml) exclude hyperparathyroidism. RA Factor negative.

Pathological examination revealed that the chalky white material was a tophaceous deposit with an associated aggregates of dissolved crystals which are surrounded by reactive mononuclear fibroblast, mononuclear inflammatory cells and giant cells. Simple microscopy show urate like crystle. Smear and culture tests of the chalky white material did not show any bacteria or acidfast bacilli. These feature suggestive of gout.

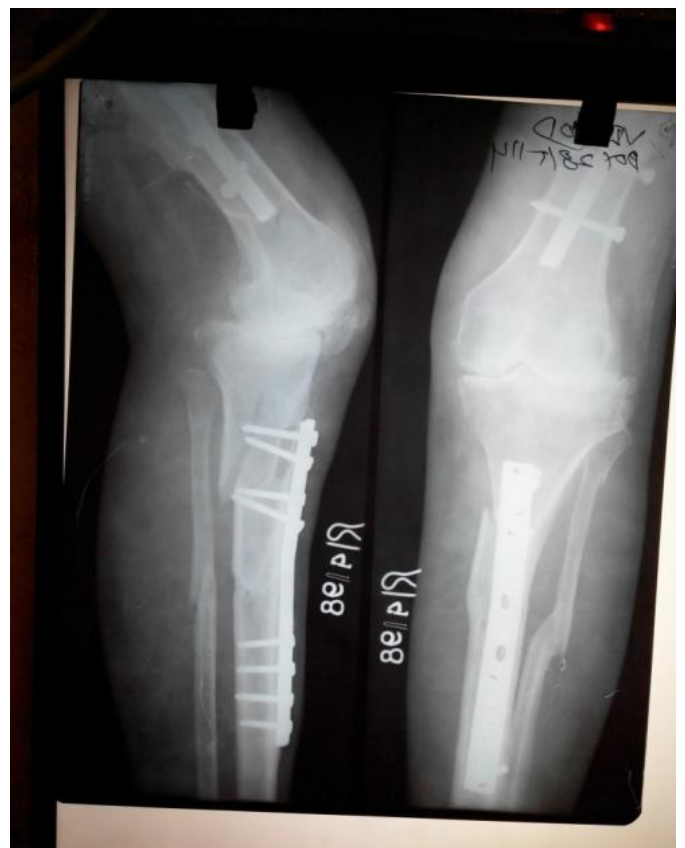

Fig-1 10 year old implant with refracture of proximal tibia

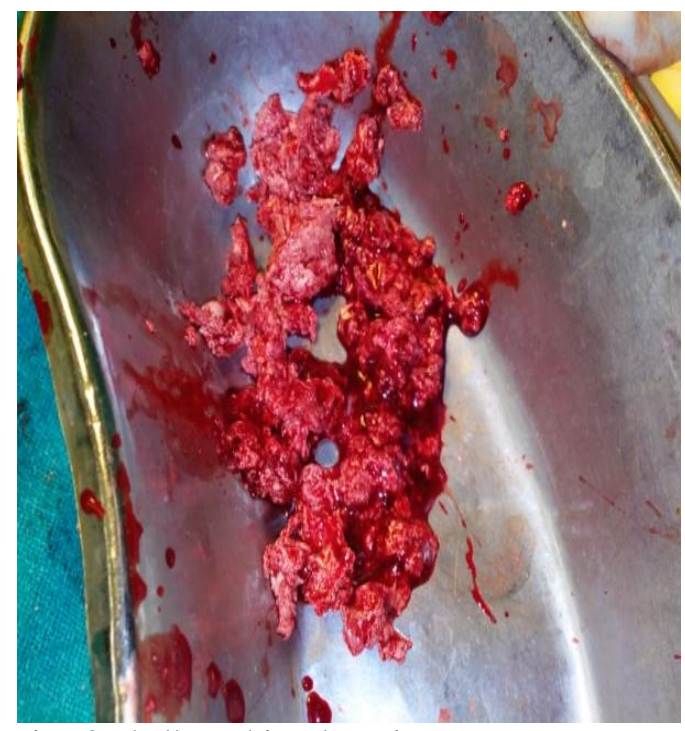

Fig- 3 chalky white deposits

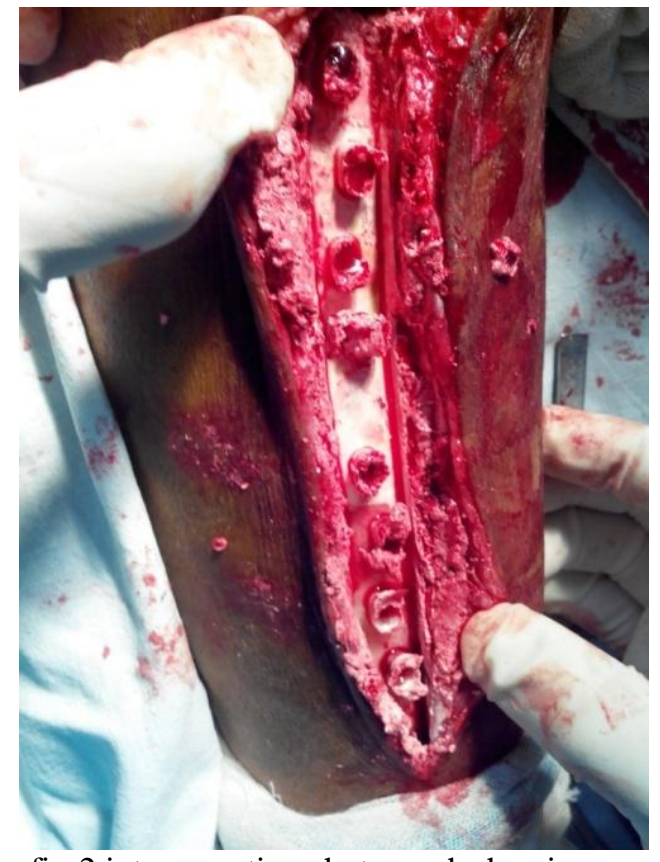

fig-2 intraoperative photograph showing chalky white deposit around implnt and inside the fracture

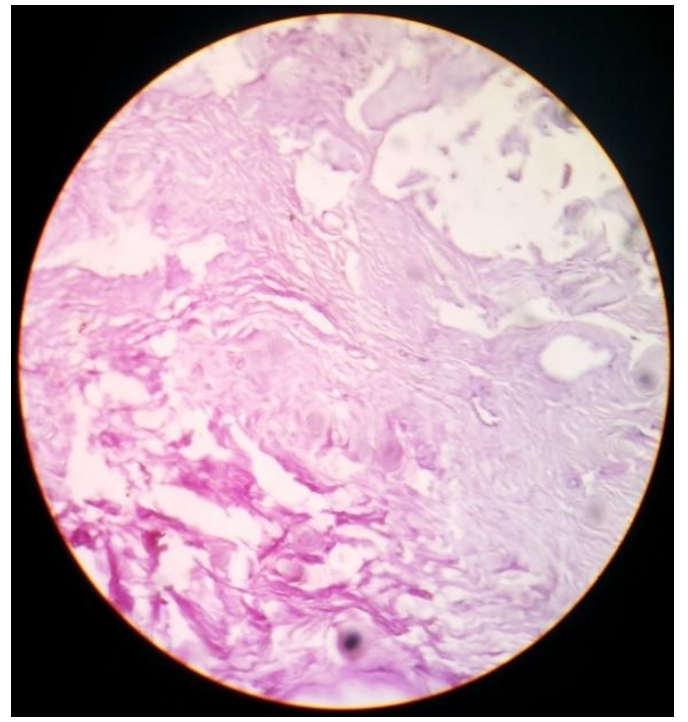

fig- 4 histopathology shows aggregates of dissolved crystals which are surrounded by reactive mononuclear fibroblast, mononuclear inflammatory cells and giant cells. 


\section{Discussion}

Gout is a form of crystal-induced arthritis, with acute attacks occurring commonly in the first metatarsophalangeal, ankle, or knee joints. Tophi have been found in $9 \%$ to $10 \%$ of gout patients, and the most frequent sites of deposition are the external ears and subcuteneus tissue of the fingertips. We are reporting a rare case in which long term undiagnosed subclinical gout deposited tophy around the implant and fracture site and causes pathological fracture of long bone.

\section{References}

[1]. Diagnosis of gout: clinical, laboratory, and radiologic fi ndings. Schlesinger N. Am J Manag Care 2005;11:S443-S450.

[2]. Wernick R, Winkler C, Campbell S. Tophi as the initial managment of gout. Report of six cases and review of the literature. Arch Intern Med 1992;152:873-876. 3. Nishioka N, Mikanagi K. Clinical features of 4,000 gouty subjects in Japan. Ad Exp Med Biol 1980;122:47-54.

[3]. Straub LR, Smith JW, Carpenter GK, Dietz GH. The surgery of gout in the upper extremity. J Bone Joint Surg Am 1961;43: 731-

[4]. R. C. Landis and D. O. Haskard, "Pathogenesis of crystal-induced inflammation," Current Rheumatology Reports, vol. 3, no. 1, pp. 36-41, 2001.

[5]. K. N. Kelley, "Approach to the patient with hyperuricemia," in Textbook of Rheumatology, W. N. Kelley, E. D. Harris, S. Ruddy, et al., Eds., pp. 1340-1347, W.B. Saunders, Philadelphia, Pa, USA, 2nd edition, 1985.

[6]. M. A. Becker, "Hyperuricemia and gout," in The Metabolic and Molecular Bases of Inherited Disease, C. R. Scriver, A. L. Beaudet, W. S. Sly, et al., Eds., pp. 2154-2155, McGraw-Hill, New York, NY, USA, 8th edition, 2001.

[7]. R. A. Terkeltaub, "Gout,” The New England Journal of Medicine, vol. 349, no. 17, pp. 1647-1655, 2003. 